a Romènia

dossiê ] TAINÁ MACÊDO VASCONCELOS

farpado.

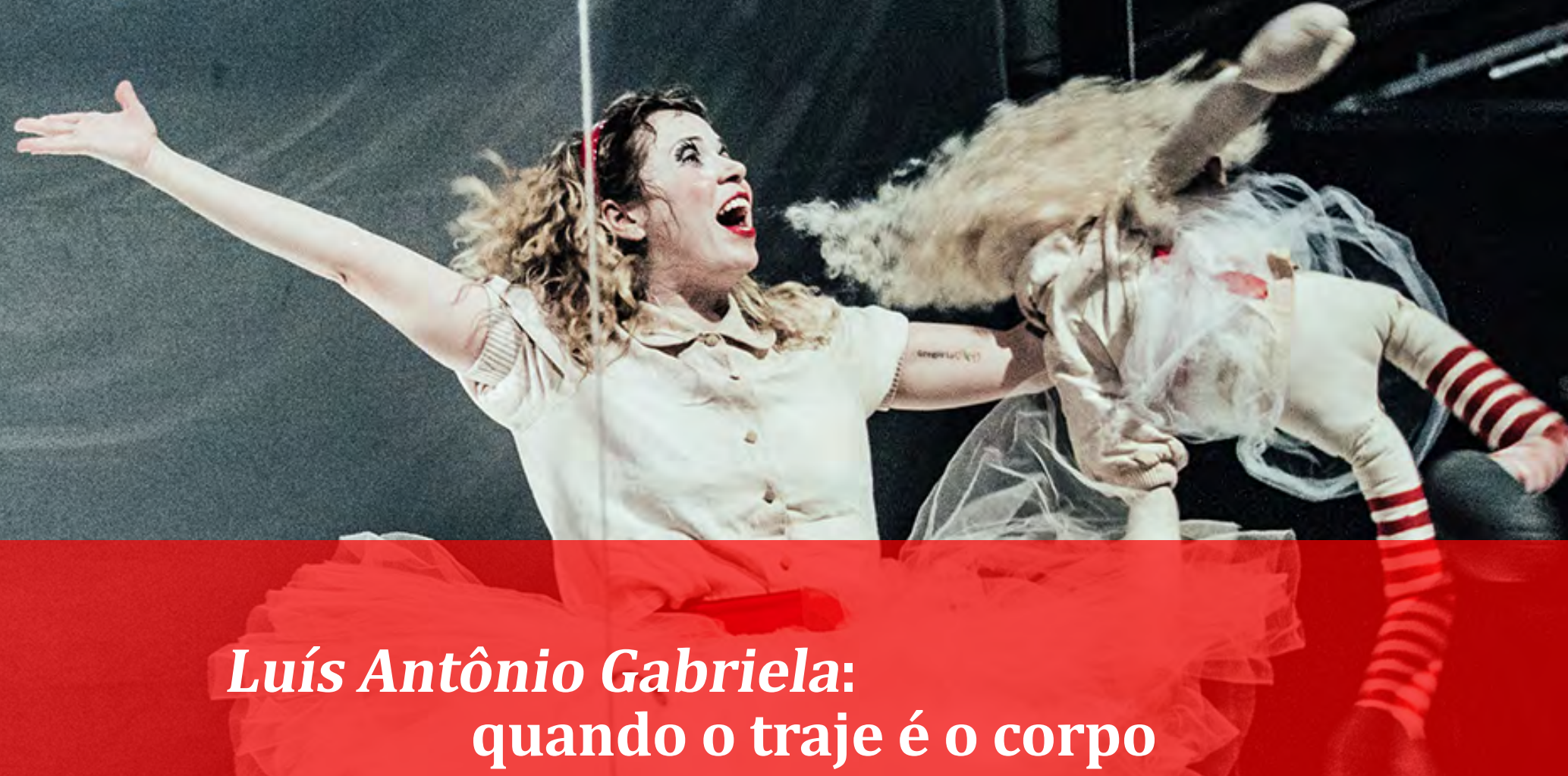

Luís Antônio Gabriela: when the body is the costume

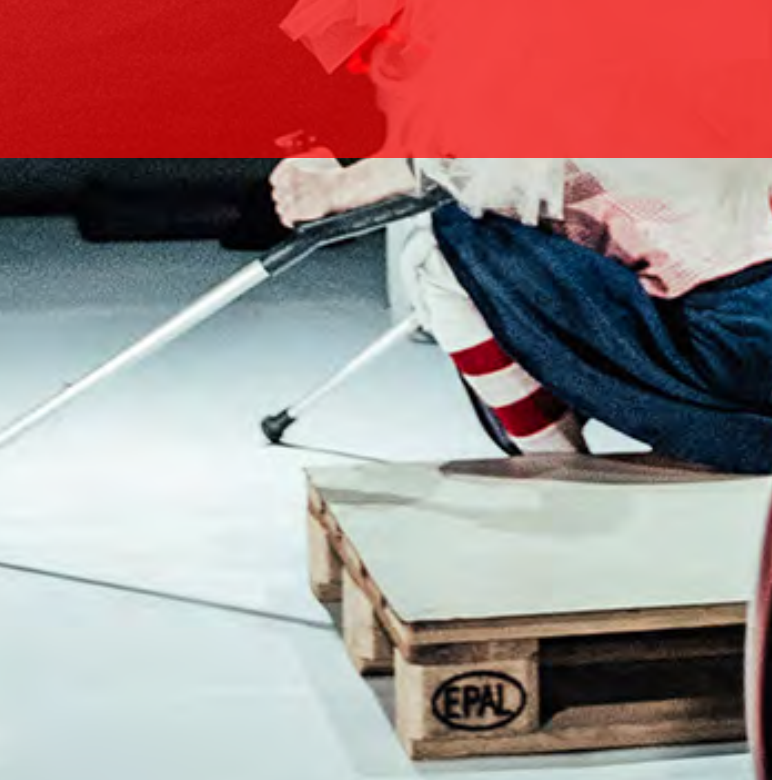




\section{TAINÁ MACÊDO VASCONCELOS 1}

ORCID: http://orcid.org/0000-0003-3726-3747

[resumo] Em tempos de guerrilhas urbanas, esse artigo apresenta a análise do traje de cena do espetáculo Luís Antônio Gabriela, da Cia. Mungunzá de Teatro. A protagonista é uma travesti, amada e incompreendida por sua família. 0 drama é autobiográfico, o diretor do espetáculo, Nelson Baskerville (2012), é irmão de Luís Antônio. 0 objetivo dessa pesquisa é compreender o traje de cena como integrante de um microcosmo dentro da encenação (VIANA, 2010), estabelecendo relações entre corpo e traje, e colaborando para a difusão do teatro enquanto posicionamento político e social. A metodologia aplicada é qualitativa, observando entrevistas realizadas, além do cruzamento de dados com publicações sobre a companhia e sobre o processo de montagem.

\section{[palavras-chave] Traje de cena. Cia. Mungunzá de Teatro. LGBTI.}

[abstract] In times of urban guerrillas, this article presents an analysis of Cia. Mungunzá de Teatro's play Luís Antônio Gabriela costume. The protagonist is a transvestite, loved but misunderstood by her family. The drama is autobiographical, since the director of the play, Nelson Baskerville (2012), is Luis Antônio's brother. The purpose of this research is to understand the costume as part of a microcosm within staging (VIANA, 2010), establishing relationships between body and costume, and collaborating for the diffusion of theatre as a political and social statement. The applied methodology is qualitative, observing interviews, as well as cross-referencing data about the company and the play.

[keywords] Costume design. Cia. Mungunzá de Teatro. LGBTI.

Recebido em: 23-03-2019.

Aprovado em: 10-06-2019.

\footnotetext{
1 Doutoranda pelo Programa de Pós-Graduação em Artes Cênicas da Universidade de São Paulo, e professora assistente da Licenciatura em Teatro da Universidade Federal do Amapá. E-mail: tainamacedo@ usp.br. Lattes: http://Lattes.cnpq.br/0518088082916895.
} 


\section{Abra a sua mente}

Nos dias atuais, ainda estamos discutindo a criminalização da violência e do preconceito contra pessoas LGBTI no Brasil. O projeto de Lei da Câmara dos Deputados no 122/06, criado por iniciativa da deputada Iara Bernardi em 2001, prevê a inclusão na lei antirracismo dos crimes oriundos da discriminação e do preconceito de gênero, sexo, orientação sexual e identidade de gênero. Estamos em 2019 e o Supremo Tribunal Federal se posicionou a favor da criminalização da homofobia.

Em 2018, em todo o Brasil houve 420 mortes de pessoas LGBTI, segundo o Grupo Gay da Bahia, uma das poucas organizações que produzem relatórios sobre esses dados no Brasil (LGBTFOBIA, 2019). Os gays e transexuais são os mais atingidos, seguidos pelas lésbicas e pelos bissexuais. Segundo o relatório da Transgender Europe, entre 2016 e 2017 aconteceram 325 assassinatos de pessoas transgêneras em 71 países; dentro dessa pesquisa o Brasil registrou 171 casos nesse período. É fato. 0 Brasil é um dos países que mais mata pessoas LGBTI (LGBTFOBIA, 2019).

É tempo de guerra. A comunidade LGBTI tem se mobilizado e reivindicado seus direitos. Tem sido assim nas ruas, na política, nas instituições, em todos os lugares, e não é diferente nas artes. Em muitas ocasiões, a arte cumpre sua função social, ressocializando indivíduos, provocando questionamentos que geram mudança de comportamento e inserindo socialmente aqueles que são considerados marginalizados. A partir de uma experiência pessoal, é possível que outras pessoas questionem as suas próprias vivências. Dessa forma, a fruição artística permite que os espectadores reflitam e tomem consciência de diferentes fatores que os envolvem. Essas não são as únicas funções da arte, mas é sobre esse aspecto que este trabalho está focado.

As questões políticas são extremamente relevantes, e estão refletidas na condição social da travesti. Esta pesquisa apresenta a análise dos trajes de um espetáculo teatral em que a protagonista é uma travesti, sua relação com a família e com a vida. Luís Antônio Gabriela é um espetáculo da Cia. Mungunzá de Teatro, com argumento e direção de Nelson Baskerville.

\section{Cia. Mungunzá e Luís Antônio Gabriela}

Em meados dos anos 2000, um grupo de estudantes de teatro se reuniu para formar uma companhia teatral. 0 intuito era produzir espetáculos sobre o que eles gostavam a partir de uma perspectiva brechtiana e, portanto, dialética. 0 nome veio de uma cena do espetáculo Terça insana, que os estudantes foram assistir, na qual o ator, imitando a cantora Maria Bethânia, tentava recordar o que compõe o tabuleiro da baiana (música de Dorival Caymmi), e uma das coisas citadas foi o mungunzá2.

\footnotetext{
2 Mungunzá é um prato comum no estado da Bahia e em outros estados do nordeste brasileiro, preparado com milho, leite de coco, cravo e canela.
} 
O grupo de jovens atores não tinha nenhuma condição financeira, mas mesmo assim fez uma proposta para o diretor Nelson Baskerville, para montarem o primeiro espetáculo da Cia. Mungunzá de Teatro. A estética dos trabalhos de Baskerville interessava muito aos atores. Eles se reuniram e montaram Por que a criança cozinha na polenta e estrearam em 2008 (MATE, 2018).

A primeira temporada foi quase vazia, exceto pelos amigos e familiares. Houve substituições no elenco; da formação original, apenas Marcos Felipe e Sandra Modesto continuaram. Entraram Lucas Bêda, Verônica Gentilin e Virginia Iglesias. Assim, estava formada a Cia Mungunzá. A segunda temporada foi um sucesso, casa lotada com os amigos dos amigos.

Após esse espetáculo, Nelson Baskerville contou aos atores da Cia. Mungunzá a história do seu irmão Luís Antônio, e a saga que sua irmã, Maria Cristina, fez para reencontrar Luís Antônio em Bilbao, na Espanha (BASKERVILLE, 2012, p. 29). 0 grupo todo decidiu que esse seria o tema do novo espetáculo da companhia. Um espetáculo. Uma homenagem. Um pedido de perdão.

Luís Antônio era o filho adotado de uma família de nove irmãos, seis filhos do pai com Gladys, que morreu no parto de Nelson, e três filhos de um segundo casamento com Doracy, segunda mãe para o diretor. Luís Antônio era um menino feminino, e com sexualidade aflorada, se destacava na cidade de Santos, onde todos o conheciam como o gay. Quando era pequeno, dava trabalho em casa e na escola, abusou do irmão mais novo (Nelson) e transava com todos que se permitissem. Os pais não aceitavam seu comportamento, as outras pessoas menos ainda. Em casa, estava acostumado a apanhar, e na rua era xingado com frequência. No dia em que saiu de casa, a família sentiu um alívio, pois a fama de Luís Antônio corria pela cidade. Depois desse dia, ele nunca mais voltou para morar com sua família. Morou com um avô, e depois com amigas e amigos, até falecer em um convento de freiras em Bilbao. Fazia shows com dublagens, fazia programa, fez o que quis da maneira que deu. A família se afastou e perdeu o contato. Na Espanha, fez sucesso em Bilbao como Gabriela. Fez muito dinheiro cantando na noite e se prostituindo. Mas a generosidade de Gabriela também era conhecida, ela ajudava qualquer um, com dinheiro ou com sexo. A aids, uma encefalopatia e uma hepatite $C$ não a deixaram seguir nos palcos. A irmã, Maria Cristina, conseguiu encontrar com Gabriela em Bilbao, e foi a única da família que se aproximou antes da morte dela.

No posfácio do livro de Nelson Baskerville, Maria Cristina, irmã do autor, relata que todos os amigos de Luís Antônio em Bilbao eram "unânimes em enaltecer sua generosidade, simpatia e lealdade. E sobre seu trabalho, com muito, muito glamour nos vidrilhos, lantejoulas e canutilhos bordados nos trajes, costurados e bordados por [ela] mesma" (BASKERVILLE, 2012, p. 243-244).

A vida de uma criança LGBTI não é fácil, principalmente quando a família não assume e não respeita as individualidades de cada um. Quando o preconceito é maior do que o amor e o respeito, as ações acabam se tornando violentas. Depois de conhecer umas amigas mexicanas que vinham de um povoado onde ser travesti era normal, Luís Antônio entendeu que nasceu em um corpo errado, e também havia nascido no lugar errado (BASKERVILLE, 2012). Ao se deparar com esse relato cruel e verdadeiro, a Cia. Mungunzá não teve outra escolha a não ser montar um espetáculo sobre Luís Antônio-Gabriela. 


\begin{abstract}
Dizem que, quando Moreno criou o psicodrama, chegaram a atestar o fim do teatro, pois, a partir do momento que você pudesse dramatizar sua própria vida, a necessidade de assistir ao teatro terminaria. Mas não foi o que aconteceu. 0 teatro sobreviveu. Com todos os seus inimigos e concorrentes soltos. Porque a experiência de atores ao vivo, a presença, o corpo e a respiração conduzem a plateia a lugares inóspitos. Lugares que a maioria das pessoas não está acostumada a visitar. É dessa matéria que é feito o teatro (BASKERVILLE, 2012, p. 136).
\end{abstract}

Dessa matéria o espetáculo Luís Antônio Gabriela está feito, da própria vida. É o retrato de uma família brasileira, que continuará sendo vivenciado por inúmeras famílias. 0 posicionamento social está delineado, todos merecem respeito, as escolhas que cada um faz e vive cabe a cada indivíduo. 0 teatro sobreviveu para que essa e tantas outras histórias pudessem ser encenadas várias vezes, por transexuais, mulheres, homens e até objetos. Assim, dois irmãos puderam se reconciliar por meio da arte.

\title{
0 espetáculo
}

Luís Antônio Gabriela estreou em março de 2011 no Centro Cultural São Paulo. A companhia recebeu uma verba de 80 mil reais para a montagem desse espetáculo, sendo 30 mil advindos do Concurso de Apoio a Projetos de Promoção das Manifestações Culturais com Temática LGBT do Estado de São Paulo, e 50 mil de patrocínio particular.

0 processo de montagem contou com a contribuição de Maria Cristina e dos familiares e amigos de Luís Antônio que foram sendo encontrados durante a pesquisa. Fotografias, relatos, cartas e lembranças foram retomados para que esse trabalho pudesse ser construído. Foi uma viagem de volta à infância turbulenta dos nove irmãos, a discriminação sofrida na cidade de Santos, e a ausência de um irmão mais velho que não recebeu o afeto que deveria.

Toda essa carga emotiva era refletida sobre os espectadores. Alexandre Mate (2018) afirma que "pela beleza da obra e seu caráter demovente: uma exposição de chagas emocionais vivas - correspondendo a tantas e semelhantes outras das pessoas na plateia - dificilmente se sai do mesmo modo àquele que se entrou" (MATE, 2018, p. 192). 0 espectador entra no espaço cênico com todos os seus preconceitos e não consegue sair da mesma forma, pelo simples fato de conhecer uma nova realidade, que se choca com os padrões observados até então.

Marcos Felipe (2018) afirma que Luís Antônio Gabriela é uma peça que traz dentro uma revolução silenciosa.

Revolução silenciosa é quando um espetáculo modifica o público, ou a partir daquele momento o público passa a enxergar as questões abordadas no espetáculo de outra forma, sem que necessariamente ele se defenda numa bandeira LGBT, ou que ele seja panfletário. Isso é o que eu chamo de uma revolução silenciosa (FELIPE, 2018, p. 41). 
Durante o espetáculo, a plateia é convidada a mergulhar nos aspectos íntimos da vida de uma travesti, seus desejos sexuais, seus medos e alegrias. Não é possível sair da mesma forma que se entrou, porque a ação é inspirada na realidade, que para muitos é desconhecida com tanta profundidade. Em Luís Antônio Gabriela assistimos a vida de uma pessoa, que poderia ser eu ou você - essa empatia gerada é fruto daquela revolução silenciosa.

A dramaturgia foi desenvolvida a partir dos fragmentos coletados nos encontros com os familiares e amigos, além dos objetos que foram sendo trazidos também. Na ficha técnica o argumento do espetáculo é de Nelson Baskerville, com intervenções dramatúrgicas de Verônica Gentilin, a partir dos relatos de Doracy, Maria Cristina, Nelson Baskerville, Serginho e das cartas de Gabriela.

Os atores também faziam suas proposições, que eram orquestradas pelo diretor. Em cena estão Day Porto, Gustavo Sarzi, Lucas Bêda, Marcos Felipe, Sandra Modesto, Verônica Gentilin e Virginia Iglesias. Day Porto e Gustavo Sarzi são responsáveis pelas músicas do espetáculo executadas ao vivo. Lucas Bêda representa o pai, Pascoal, e o cabelereiro Serginho. Marcos Felipe interpreta Luís Antônio. Sandra Modesto representa a irmã e a mãe Gladys. Verônica representa Nelson. E Virginia, a madrasta Doracy.

A iluminação e a cenografia são de Marcos Felipe e Nelson Baskerville, e esta apresenta telas pintadas por Thiago Hattnher (figura 1). A luz do espetáculo é pontual e o efeito de meia luz é frequente, apenas o que precisa ser visto é iluminado. Na maior parte do tempo, quando existe iluminação, a luz é branca e forte; porém, para alcançar efeitos com a luz, os atores jogam tecidos vermelhos e amarelos sobre os refletores. 0 controle da luz é feito pelos atores em cena.

A cenografia é complementar à encenação, não excede e nem falta. 0 palco parece vazio pelo escuro e, ao mesmo tempo, cheio de objetos que não fazem sentido. Aos poucos cada, adereço vai se tornando útil, desde a maca que carrega a mãe Gladys e a Gabriela no final da vida, ao letreiro luminoso que serve de legenda para as cenas, e as pinturas que apresentam corpos, homens, mulheres, pênis e seios, em posições sensuais. No palco, tudo é significante; um aglomerado de cadeiras forma a camionete rural de Pascoal e uma moldura com lâmpadas é um camarim onde Gabriela aparece desnuda.

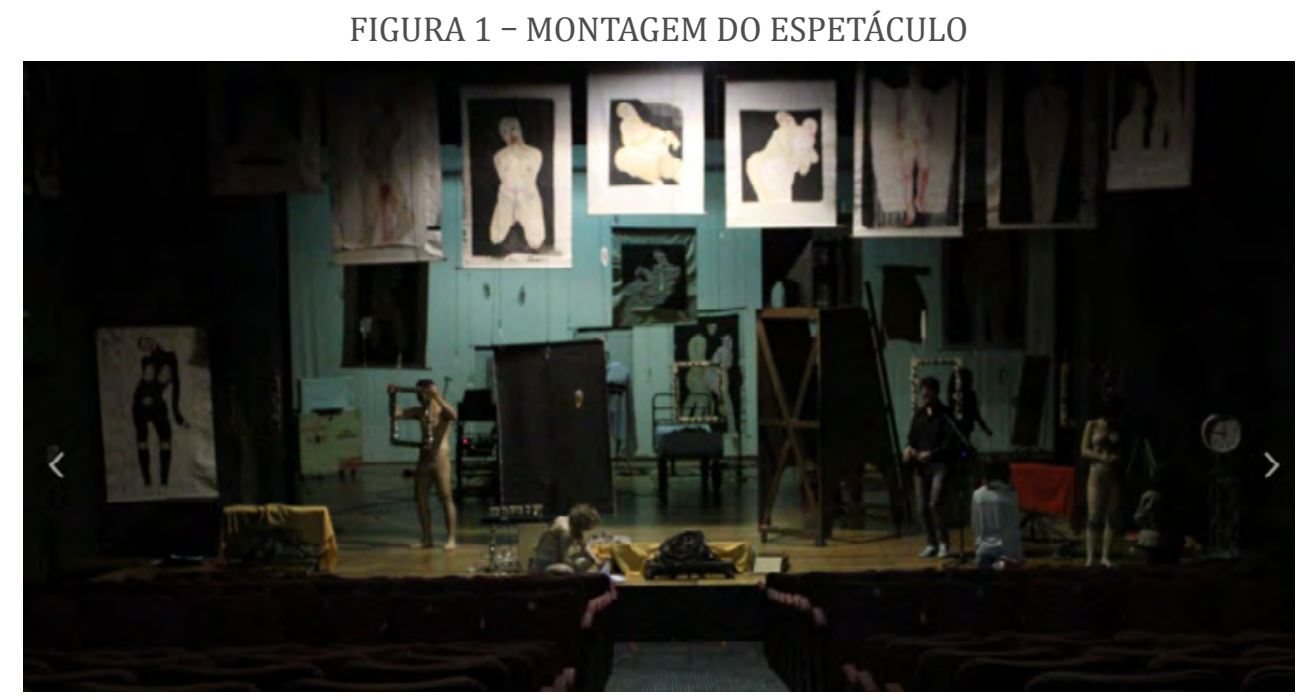

FONTE: CIA. MUNGUNZÁ DE TEATRO. Luís Antônio Gabriela. [2011?]. 1 fotografia. Disponível em: https://www.ciamungunza.com.br/luis-antonio-gabriela. Acesso em: 13 jul. 2019. 


\title{
Os trajes e os corpos
}

Os trajes cênicos do espetáculo são assinados por Camila Murano, que também foi assistente de direção de Nelson Baskerville. Os figurinos foram se constituindo a partir dos ensaios. Marcos Felipe (2018) afirma que o resultado final é fruto do costume do próprio grupo de ensaiar com roupas interiores:

\begin{abstract}
A Mungunzá é uma companhia que ensaia, por uma característica própria, seminua. Quando a gente entra na sala de ensaio, todo mundo está só de calcinha e sutiã, ou só de cueca. A gente sempre ensaia desse jeito, não tem aquela roupa de ensaio confortável, ou ensaia de cueca ou calcinha e sutiã. Eu acho que isso é um fator determinante para a criação, porque quando começamos a improvisar, logo, o nosso corpo estava muito exposto do ponto de vista de quem estava olhando as cenas, e começamos a trabalhar com uma luz, que era uma luz branca e que só funcionava quando a gente jogava um tecido vermelho, ou amarelo em cima. Então, a gente começou a trabalhar com as roupas pós-cirúrgicas, com o nude como proposta mesmo. Como queríamos uma roupa pós-cirúrgica acabamos caindo, claro, na questão da cor nude. A gente começou a trazer todos esses figurinos pós-cirúrgicos, porque existia um entendimento nosso, até pela construção do cenário, que tinha bolsas de soro penduradas em todos os cantos, de que era quase que uma relação de cortar na própria carne, tanto do ponto de vista do Nelson, de estar cortando para expor a história, logo, uma relação pós-cirúrgica, como as inúmeras intervenções cirúrgicas que a Gabriela sofreu para chegar no corpo que ela tinha. Como tinha esse lugar hospitalar dado pela encenação, e dado pelas propostas de cena, ir para o nude e para roupa pós-cirúrgica quase que não teve outro caminho (FELIPE, 2018, p. 48-49).
\end{abstract}

Da roupa de ensaio e da temática das cirurgias plásticas e dos problemas de saúde envolvidos, surge a ideia para vestir roupas pós-cirúrgicas. Sutiãs de compressão, cintas, macacões de compressão, calcinhas e shorts, essas são as peças de base do figurino, e outros elementos eram sobrepostos a esses. Camila Murano (2018) também fala da sua relação com essa decisão.

A escolha das roupas íntimas e cirúrgicas está ligada à temática da sexualidade e transexualidade de Luís Antônio Gabriela. 0 teatro épico brechtiano não pede verossimiIhança e essa autonomia e liberdade que eu desejava dar aos atores através de um figurino simbolicamente do nu, visava também permitir que cada personagem pudesse transitar pela não linearidade cronológica da história, também livremente, podendo ir de um bebê a um velho, ou ir de um garoto adolescente a um velho travesti, ou até de um caricato fantasma a uma jovem mulher. $\mathrm{E}$ ao mesmo tempo as roupas cirúrgicas refletiam também a busca pela transformação do próprio corpo de Luís Antônio, a 
não aceitação de si mesmo, a ideia de ter nascido no corpo errado, que fez com que cirurgicamente ele fosse transformando seu corpo num corpo de mulher, até a total deformidade, como podemos ver ao longo da peça. Era preciso vestir desnudando, o simbolismo do nu também revela o desnudar-se, a exposição da história verídica de uma família, que expõe corajosamente indivíduos e relações através de temas sensíveis e polêmicos como abuso, preconceito, discriminação, homofobia, pedofilia, racismo, homossexualidade, transexualidade, abandono, negligência, isolamento, violência, doenças, morte e outros. A escolha do nu simbólico traduzido nessas peças de vestuário tem também a intenção de aproximar o espectador como um espelho dele mesmo, nus somos todos iguais (MURANO, 2018).

A partir do depoimento da figurinista, observa-se que a característica inicial do grupo permanece nessa montagem, o interesse pela proposta do teatro de Bertolt Brecht3. Os trajes cênicos de Brecht também refletiam a simplicidade e eram carregados de significação. "Apesar de toda a simplicidade, as conquistas dos figurinos de Brecht são imensas. No aparente despojamento está a grandiosidade, a capacidade de revelar tanto com tão pouco" (VIANA, 2010, p. 212).

FIGURA 2 - ATORES EM CENA REPRESENTAM A FAMÍLIA

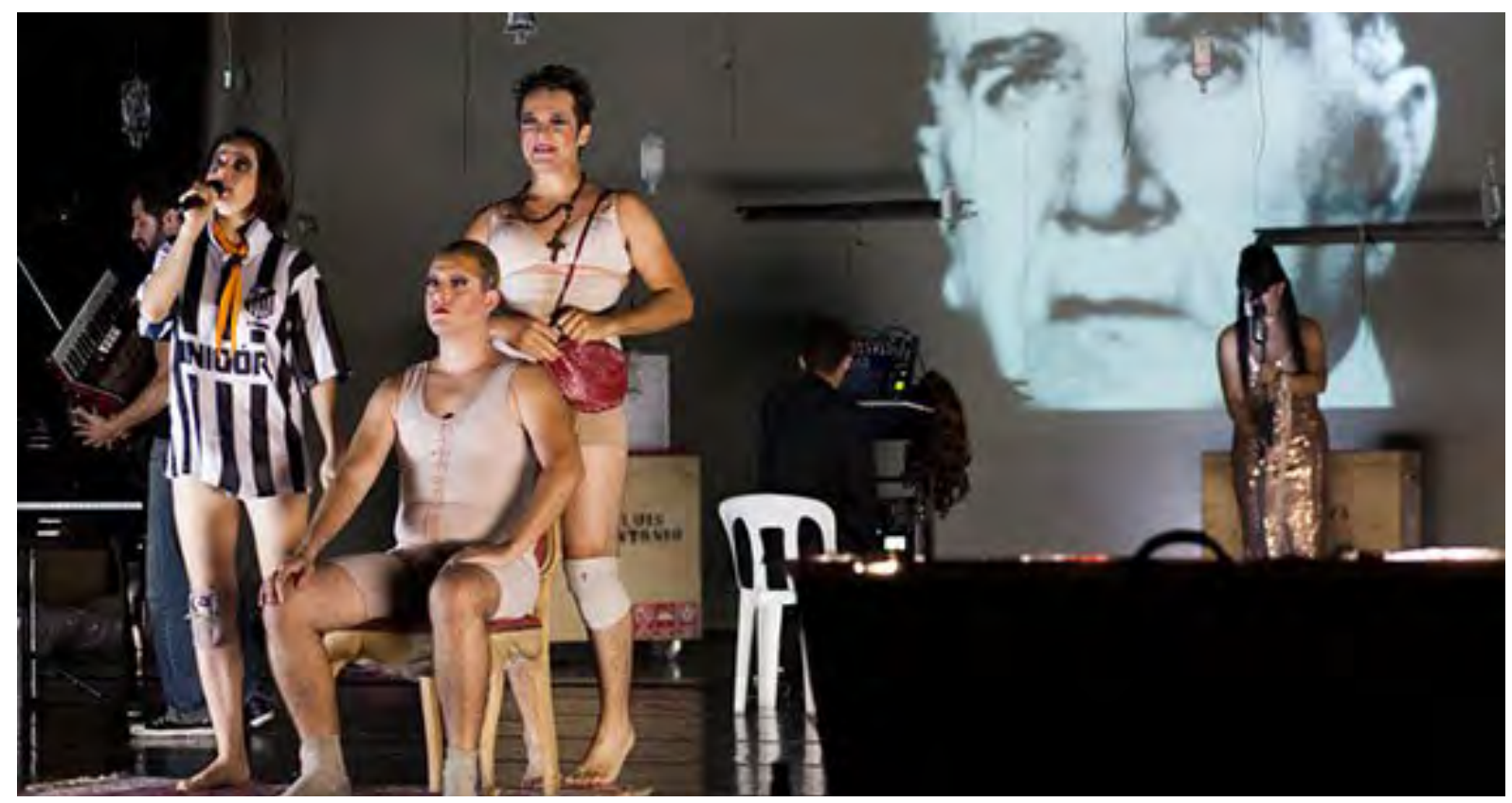

FONTE: CIA. MUNGUNZÁ DE TEATRO. Luís Antônio Gabriela. [2011?]. 1 fotografia. Disponível em: https://www.ciamungunza.com.br/luis-antonio-gabriela. Acesso em: 13 jul. 2019.

3 Dramaturgo e encenador alemão do início do século XX, conhecido pela criação do teatro épico, com a presença forte do narrador em cena, responsável pelo rompimento da quarta parede imaginária do teatro e, por consequência, pela mobilização do espectador como elemento ativo no fazer teatral. 
As roupas pós-cirúrgicas têm essa característica de significar muito, tendo em vista o tema recorrente do hospital pelas alterações no corpo da protagonista, ao mesmo tempo em que outros elementos poderiam ser rapidamente adicionados a essa roupa base. Por exemplo, Pascoal era representado por um par de meias e uma careca feita de silicone, a mãe Gladys por um lençol branco, Nelson aparece com uma camisa de futebol, e Luís Antônio com uma bolsa (figura 2).

\section{FIGURA 3 - O ATOR LUCAS BÊDA NA CENA DO CABELEREIRO COM TRAJE PÓS-CIRÚRGICO}

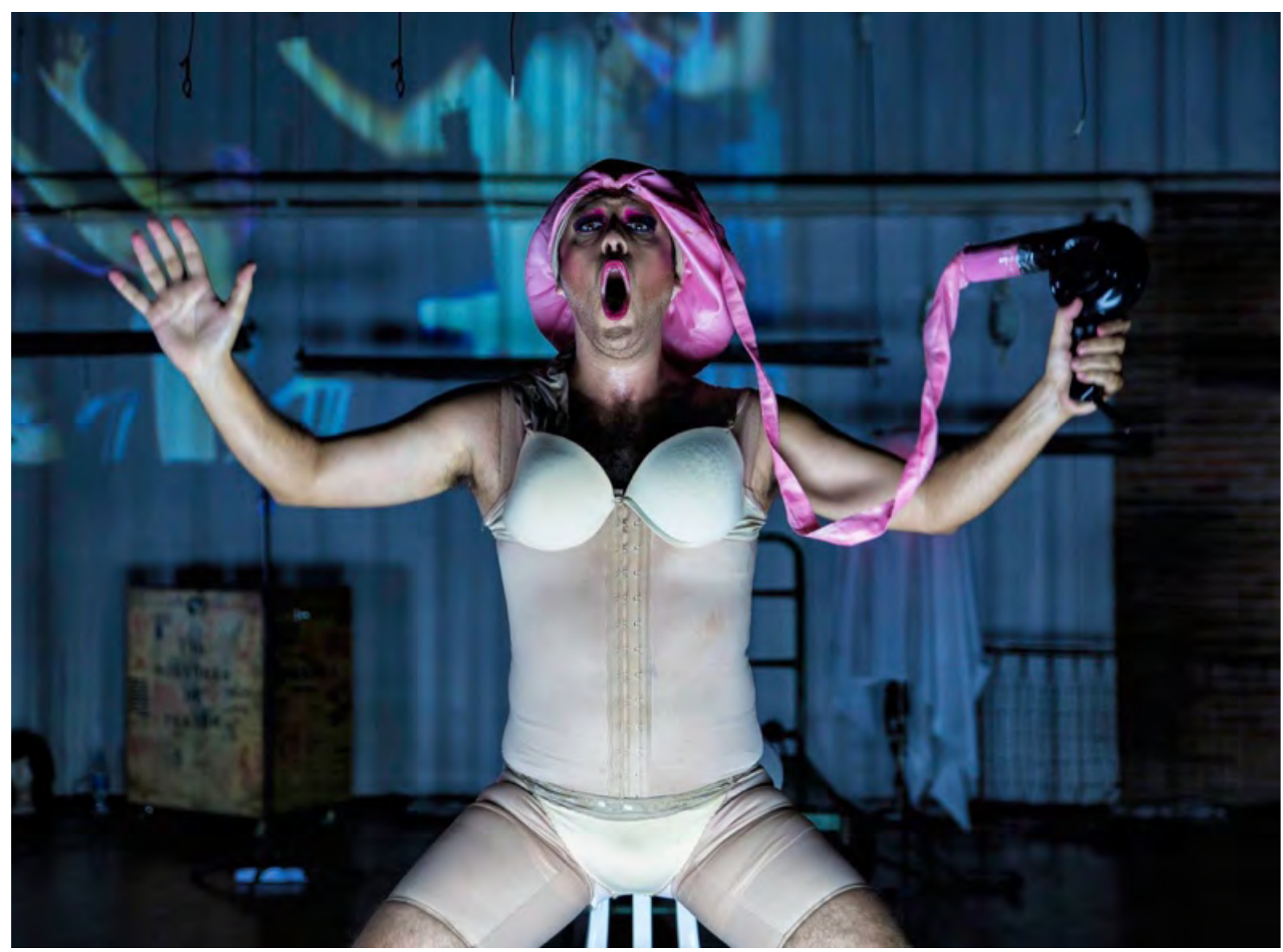

FONTE: IEMINI, Victor. Luís Antônio Gabriela. [2011?]. 1 fotografia. Disponível em: https://www. ciamungunza.com.br/luis-antonio-gabriela. Acesso em: 13 jul. 2019.

Lucas Bêda, ao interpretar Serginho, o cabelereiro, tira o par de meias e a careca e põe uma touca de salão de beleza ligada a um secador de cabelo (figura 3). A troca de adereços é rápida e prática, produzindo o efeito desejado para representar várias personagens com um elenco reduzido.

Da experiência com o material disponibilizado pela família e pelos amigos de Luís Antônio, Camila Murano (2018) percebeu que poderia criar um ambiente como se fosse um álbum de família e todas as recordações que são inerentes a esse objeto. 
Essa escavação ao passado além do conteúdo que íamos colecionando, tinha cheiro, cor, texturas, alma...e traziam assim as primeiras inspirações para essa criação, com isso surgiu em mim o desejo de transportar para o palco através das vestes das personagens com suas cores, formas e texturas uma atmosfera de um velho álbum de família. Surgiu o desejo de passar para o público a sensação de estar folheando um álbum antigo (MURANO, 2018).

Estão em cena o retrato da família, da morte da primeira mãe, da camionete rural, da violência, do abuso, do salão de beleza, dos shows, da vida e da morte. Todos esses retratos foram construídos em cima dos trajes pós-cirúrgicos e com poucos elementos que eram inseridos.

A transformação do corpo de Gabriela acontece por meio do traje. 0 ator Marcos Felipe veste no meio do espetáculo um macacão de renda, com bolsos que aos poucos vão se enchendo de bolsas de soro, desfigurando aquele corpo, produzindo volumes estranhos, representando o deslocamento do silicone aplicado no corpo da protagonista.

A relação com o corpo é intrínseca ao trabalho do ator para a construção da personagem. Nesse caso, mais ainda. 0 mesmo ator representava todos os períodos da vida de uma travesti: infância afeminada, fase adulta dos brilhos e lantejoulas e a deformação dos procedimentos estéticos de pouca qualidade. Sobre esse processo, Marcos Felipe afirma: "quando eu coloco o macacão no meio do espetáculo para o final, já é um lugar de total deformação do corpo do Luís Antônio, e a partir do momento que visto, eu começo a trabalhar com mais 15 quilos no meu próprio corpo, que são as bolsas de soro" (FELIPE, 2018, p. 53) (figuras 4 e 5).

FIGURA 4 - O ATOR MARCOS FELIPE E A ATRIZ SANDRA MODESTO REPRESENTAM GABRIELA E MARIA CRISTINA

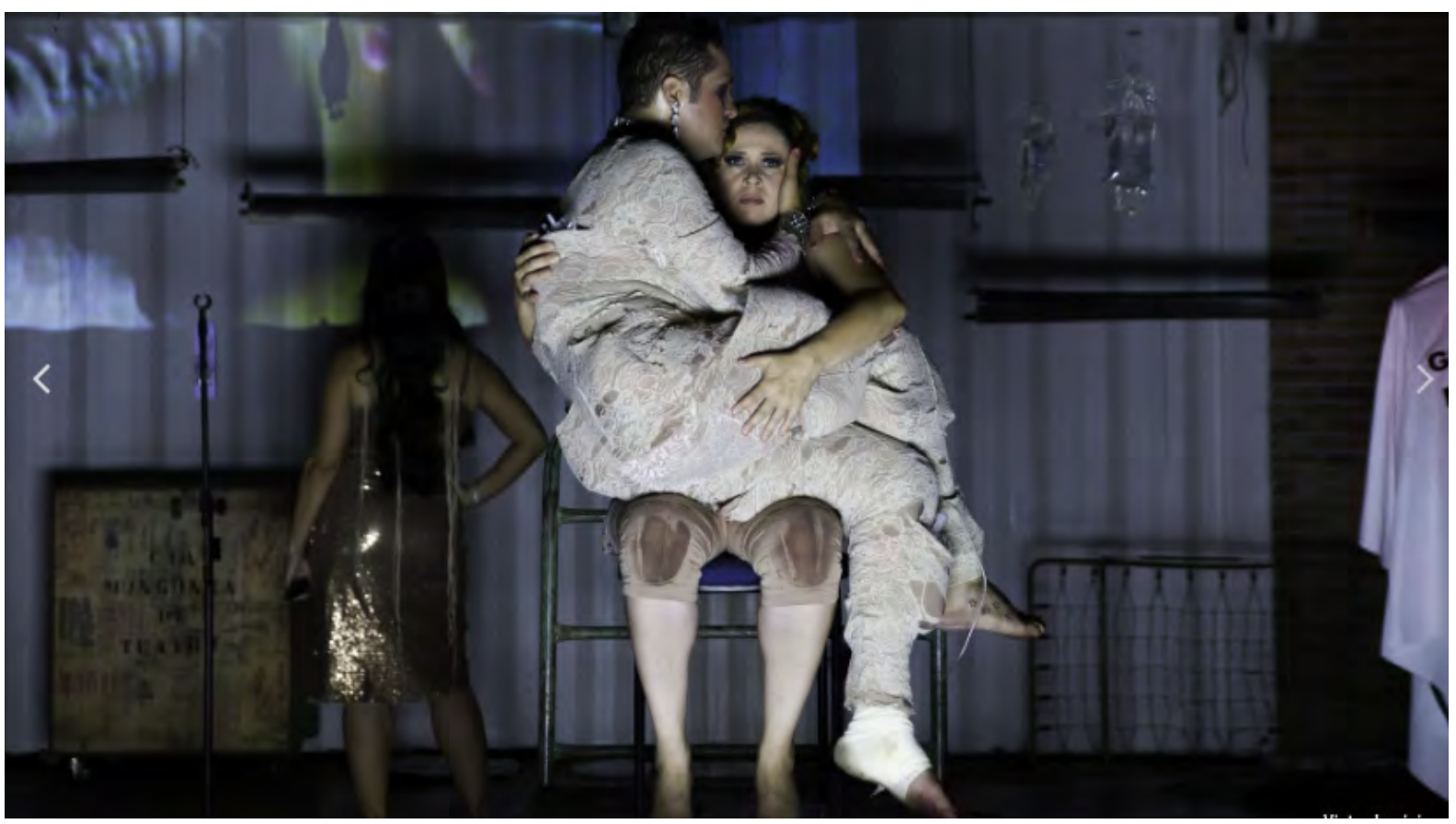

FONTE: IEMINI, Victor. Luís Antônio Gabriela. [2011?]. 1 fotografia. Disponível em: https://www. ciamungunza.com.br/luis-antonio-gabriela. Acesso em: 13 jul. 2019. 


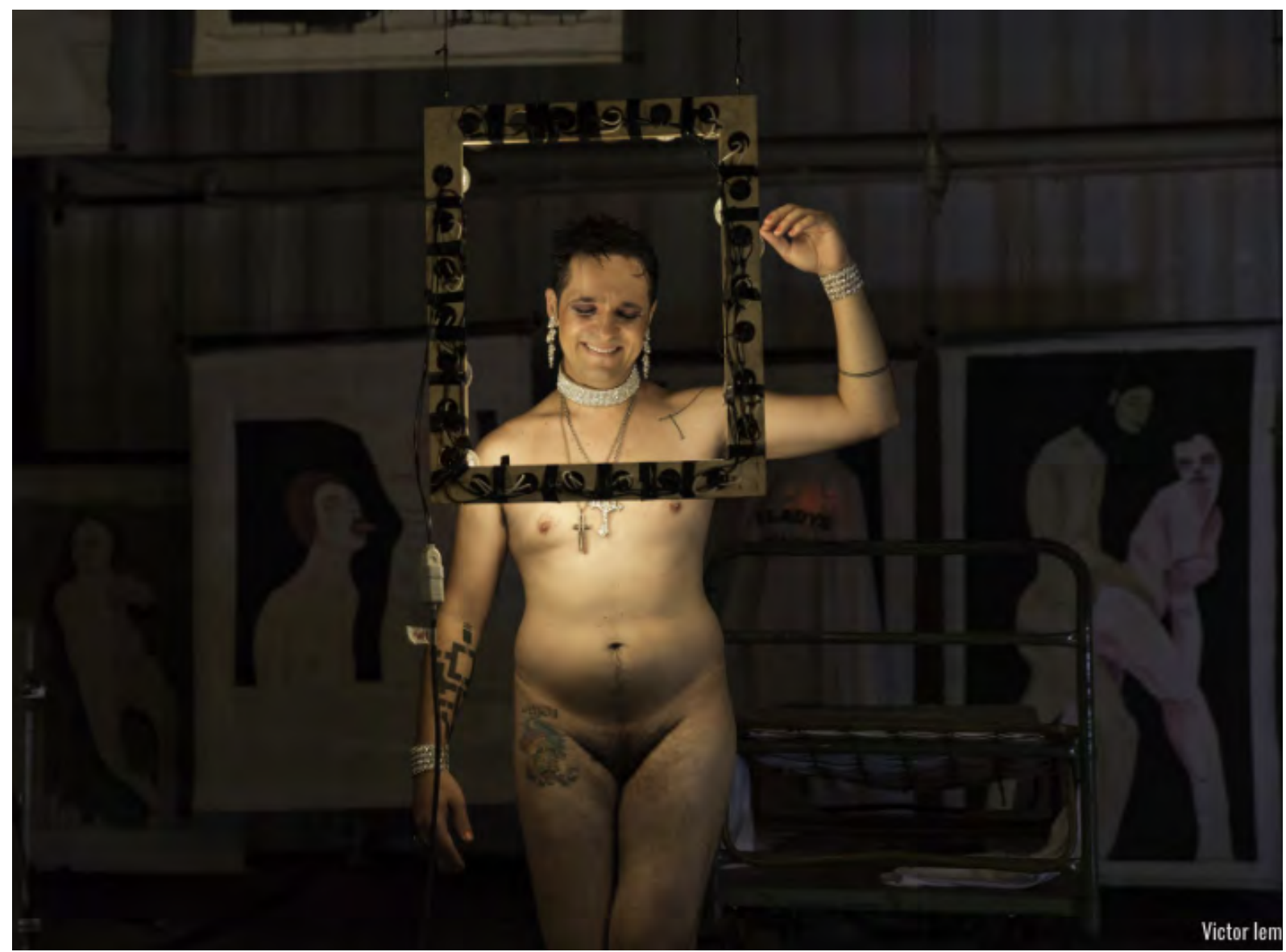

FONTE: IEMINI, Victor. Luís Antônio Gabriela. [2011?]. 1 fotografia. Disponível em: https://www. ciamungunza.com.br/luis-antonio-gabriela. Acesso em: 13 jul. 2019.

A experiência do ator é representativa. Quantos homens e mulheres vivem essa situação na realidade? Como diria Judith Butler (2003), da teoria queer, o corpo é uma construção, um conjunto de fronteiras individuais e sociais. Os corpos são moradas de consciências, e cada um tem uma experiência de vida diferente da do outro.

Baskerville (2012) lembra que Luís Antônio desde pequeno apresentava traços da homossexualidade. A feminilidade foi aflorando, o que gerou brigas em casa e na rua, todos o chamavam de "mariquinha"; Luís Antônio passou a acreditar que havia nascido em um corpo errado (BASKERVILLE, 2012, p. 52-53). Os procedimentos estéticos e as cirurgias plásticas modificaram o corpo de Luís Antônio, com enxertos de silicone de má procedência, o que acarretou deformações por todo o corpo. Luís Antônio não só mudou os trajes, como o próprio corpo, para se sentir realmente um ser humano. 0 macacão utilizado por Marcos Felipe no final do espetáculo representa esse corpo transformado e deformado por tantas mudanças.

Ainda sobre os trajes de cena e a manutenção deles, Marcos Felipe (2018) relatou que o grupo não possui um acervo de figurinos, por isso: 
Hoje, cada um, cada artista é responsável pelo seu próprio figurino, acaba o espetáculo ele leva para casa, cuida, lava o figurino, e na medida em que ele acha que o figurino está entrando numa fase muito desgastada, que está prejudicando o andamento do espetáculo, ele mesmo faz a troca do seu próprio figurino (FELIPE, 2018, p. 52).

O macacão de Gabriela precisa ser refeito com frequência, tendo em vista o peso e a fragilidade do material. Mesmo com uma sede própria e com estrutura, o grupo ainda precisa de espaço e de uma pessoa responsável pela manutenção e conservação dos trajes de cena dos espetáculos.

\section{Desdobramentos}

Luís Antônio Gabriela é um espetáculo arrebatador e polêmico. Em entrevista no início de 2018, Marcos Felipe (2018) disse que o grupo "não enxerga o Luís Antônio Gabriela como estandarte LGBT. Por mais incrível que isso possa parecer. A gente acha inclusive que o Luís Antônio Gabriela teve a dimensão que teve porque trata do ser humano e das questões de família" (FELIPE, 2018, p. 39). Sem dúvida, os problemas familiares estão presentes na vida de todos, isso faz parte da condição humana e social a que estamos atrelados. Amamos e odiamos. Por outro lado, compreendo essa fala de Marcos Felipe como uma afirmação de que não era o objetivo principal do espetáculo levantar as causas LGBTI, mas ao retratar a trajetória de vida de uma travesti, aspectos íntimos são expostos e acaba-se suscitando o debate sobre a temática.

Esse espetáculo viajou por todo o país, passando por diversos municípios, mais de 40 mil pessoas já assistiram e a maior parte delas saiu refletindo sobre as questões sociais que permeiam a vida de uma travesti. Nos debates que aconteceram após as apresentações, o público sempre questionou os atores e a equipe (FELIPE, 2018).

Nelson Baskerville (2012, p. 32) afirma que era indagado sobre a reação dele em relação à convivência com Luís Antônio quando este já estava doente em Bilbao, e até sobre o enterro dele em 2006. Baskerville (2012, p. 32) nunca mais teve contato com o irmão. E para pedir perdão e se aproximar de alguma forma, ele montou esse espetáculo com a Cia. Mungunzá.

Muitos espectadores ficam chocados quando descobrem que Marcos Felipe não é gay. "Hoje em dia, [o público LGBTI] questiona e reivindica o lugar de fala" (FELIPE, 2018, p. 55). Como um ator heterossexual pode representar uma travesti? A comunidade LGBTI exigiu o seu lugar. A partir de uma reinvindicação do Movimento Nacional de Artistas Trans (Monart), a Cia. Mungunzá de Teatro publicou em sua rede social que a atriz trans Fabia Mirassos irá apresentar a personagem Gabriela por 35 anos. Isso mesmo, Marcos Felipe continua nas primeiras cenas interpretando o Luís Antônio, e a fase adulta da Gabriela está sob a responsabilidade de uma atriz trans até 2053.

Poucos são os que tomam consciência do que podem fazer. A Cia. Mungunzá abre espaço para o diálogo e promove o empoderamento com essa ação. Não porque um ator não possa representar uma mulher, ou o inverso. Os atores e as atrizes podem representar 
deuses, animais, mulheres, e até árvores ou postes. Se não podem representar o outro, logo, não são atores. Mas não é essa a questão. 0 que aconteceu com o espetáculo Luís Antônio Gabriela foi uma tomada de consciência do poder político que o teatro sempre teve. Com isso, a Cia. Mungunzá declara publicamente que as artistas transexuais são bem-vindas e devem assumir esse e outros lugares também. A partir da integração entre todas as pessoas, observa-se uma das funções sociais da arte: neste caso, as artistas transexuais assumem mais um papel, demonstrando assim a sua representatividade.

\section{Conclusão}

Esse artigo investigou os trajes de cena do espetáculo Luís Antônio Gabriela, da Cia. Mungunzá de Teatro, a partir da relação do corpo do protagonista, uma travesti, e todas as interferências usuais nesse corpo, como as cirurgias plásticas. Assim, observou as relações com os corpos dos atores, sujeitos capazes de representar personagens que não são do mesmo sexo, como é o caso da atriz Verônica Gentilin, que representa Nelson, diretor do espetáculo e irmão de Luís Antônio.

Outro aspecto significativo é a busca por uma visualidade mais próxima à real. 0 universo LGBTI é marcado pelo estereótipo do glamour e, segundo Marcos Felipe (2018), as primeiras experiências plásticas envolviam essa ideia. Porém, no resultado final, o brilho e os paetês aparecem apenas nas últimas cenas. Os trajes pós-cirúrgicos dão conta de vestir os corpos e significar com ajuda de poucos elementos sobrepostos.

O objetivo do presente estudo foi apresentar uma análise dos trajes de cena desse espetáculo, a partir do olhar do corpo real e ao mesmo tempo modificado pelas experiências vividas por cada um. 0 traje de cena neste espetáculo sugere que somos todos corpos, e como Camila Murano (2018) afirmou: "nus, somos todos iguais". Nossos corpos contam as suas histórias de amor e repressão. Somos uma síntese dos acontecimentos marcados na pele, na consciência e no comportamento. Os resultados dessa análise indicam que ainda desconhecemos nós mesmos e, por consequência, desconhecemos o outro. A revolução silenciosa colocada por Marcos Felipe (2018) é o motor dessa ação de descoberta do outro e de si também, pois não estamos sozinhos, e ao sermos tocados pela história de uma travesti, refletimos sobre o nosso comportamento.

Esse espetáculo tem mais impacto no âmbito social, ao retratar o dia a dia de uma travesti e sua família, os problemas decorridos e a independência precária. Ao compreender o lugar do outro, o espectador reflete sobre seu próprio comportamento e suas relações sociais são afetadas por isso.

Tudo isso aumenta nossa percepção sobre a importância dos direitos LGBTI e da luta política nesse aspecto. A violência é constante e está à espreita. A luta por "nenhum direito a menos" tem que seguir. No Brasil, desde alguns anos tem sido possível registrar união estável entre pessoas do mesmo sexo; a mudança do nome social a partir da identificação do gênero também é uma vitória. Espera-se que, em breve, a lei que criminaliza a violência e o preconceito de sexo, gênero, orientação sexual e identidade de gênero se efetive na realidade cotidiana, trazendo melhoria na qualidade de vida para toda pessoa LGBTI. 
Essa pesquisa esteve limitada ao estudo do espetáculo Luís Antônio Gabriela mas, se olharmos ao redor, existem muitas outras iniciativas teatrais que abordam esse tema. Na atualidade podemos citar o espetáculo BR Trans, de Silvero Pereira, que traz à cena relatos coletados pelo ator em pesquisa de campo com travestis nas ruas de Porto Alegre (RS) e Fortaleza (CE). Outro exemplo é o espetáculo 0 Evangelho segundo Jesus, Rainha do Céu, com Renata Carvalho, que remonta a história de Jesus como uma mulher.

Um estudo mais amplo sobre a Cia. Mungunzá é necessário, para compreender outros aspectos da luta política travada por esse coletivo de artistas inquietos. A relação que eles têm experimentado no centro de São Paulo com o Teatro Contêiner e com os moradores de rua no entorno foi o mote para o último espetáculo da companhia, Epidemia Prata. Não é de hoje que o grupo expõe questões latentes à sociedade brasileira.

Dessa forma, os trajes de cena de todos os espetáculos dessa companhia, no contexto do teatro contemporâneo, assim como o estudo da manutenção e conservação deles, contribuem para o entendimento das relações humanas e dos conflitos dentro de uma perspectiva social. Enfim, estamos diante de uma obra de arte que cumpre sua função, para além da fruição. 0 teatro continua exercendo seu papel político, como uma arte efêmera, mas que permanece na memória dos participantes. Desejo que muitos outros espectadores possam fazer parte dessa revolução silenciosa.

\section{Referências}

BASKERVILLE, Nelson. Luís Antônio Gabriela. São Paulo: nVersos, 2012.

BUTLER, Judith. Problemas de gênero: feminismo e subversão da identidade. Tradução Renato Aguiar. Rio de Janeiro: Civilização brasileira, 2003.

FELIPE, Marcos. A revolução silenciosa de Luís Antônio Gabriela e o traje de cena. In: VIANA, Fausto; GIL, Maria Celina; VASCONCELOS, Tainá Macêdo (org.). Dos bastidores eu vejo o mundo: cenografia, figurino, maquiagem e mais. São Paulo: Eca-Usp, 2018. v. 3, p. 37-60. Disponível em: https://doi.org/10.11606/9788572051958. Acesso em: 14 mar. 2019.

LGBTFOBIA no Brasil: Fatos, números e polêmicas. Politize! Santa Catarina, 12 fev. 2019. Disponível em: https://www.politize.com.br/lgbtfobia-brasil-fatos-numeros-polemicas/. Acesso em: 14 mar. 2019.

MATE, Alexandre. Mungunzá: Obá! Produção teatral em zona de fronteira. São Paulo: Cooperativa Paulista de Teatro, 2018.

MURANO, Camila. [Sobre a criação do figurino]. Destinatário: Tainá Macêdo Vasconcelos. São Paulo, 28 fev. 2018. 1 e-mail.

VIANA, Fausto. 0 figurino teatral e as renovações do século XX. São Paulo: Estação das Letras e Cores, 2010. 